Dergi Ana Sayfası: https://dergipark.org.tr/tr/pub/ahbvtfd

ISSN: $2687-1912$

DOI: $10.34189 / \mathrm{tfd} .23 .01 .005$

\title{
Turizm ve Otelcilik ile Aşçılık Öğrencilerinin Bilgi ve İletişim Teknolojileri Yeterliliklerinin Belirlenmesine Yönelik Bir Araştırma: Afyon Meslek Yüksekokulu Örneği
}

(A Study on The Determination of Qualifications of Information and Communication Technologies of Tourism and Hotel Management and Cookery Students: Afyon Vocational School Sample)

\author{
*Hümeyra Töre BAŞAT ${ }^{\mathrm{a}} \quad$ Hatice YILMAZ ${ }^{\mathrm{b}} \quad$ Erdal ÖZER $^{\mathrm{c}}$ \\ ${ }^{a}$ Afyon Kocatepe Üniversitesi, Afyon MYO, Otel Lokanta ve İkram Hizmetleri Bölümü, Afyonkarahisar-Türkiye (humeyratore@gmail.com) \\ https://orcid.org/0000-0003-4064-492X \\ b Afyon Kocatepe Üniversitesi, Afyon MYO, Otel Lokanta ve İkram Hizmetleri Bölümü, Afyonkarahisar-Türkiye (hatice_guney@hotmail.com) \\ https://orcid.org/0000-0002-7488-6460 \\ ${ }^{c}$ Afyon Kocatepe Üniversitesi, Afyon MYO, Otel Lokanta ve İkram Hizmetleri Bölümü, Afyonkarahisar-Türkiye (erdalozer43@yahoo.com) \\ https://orcid.org/0000-0002-6782-4878
}

MAKALE GEÇMIŞ̇i

Gönderim Tarihi: 04.05.2020

Kabul Tarihi:

05.06 .2020

\section{Anahtar Kelimeler:}

Bilgi ve iletişim teknolojileri

Turizm ve otelcilik

Aşçılık

Meslek Yüksekokulu

\section{ÖZ}

\begin{abstract}
Günümüzde bilgi ve iletișim teknolojileri, hayatın her alanında olduğu gibi çalışma hayatında da her geçen gün önemini arttırmakta; çalışanların çalışma koşulları ve çalışma düzenlerinde büyük değişikliklere yol açmaktadır. $\mathrm{Bu}$ durum bilgi ve iletişim teknolojilerini etkili ve verimli bir şekilde kullanabilmek için gerekli bilgi, beceri ve donanıma sahip olan çalışanlar arasında olumlu anlamda farklılık yaratabilmekte ve bireylerin iş hayatında kabul görmesini hızlandırmaktadır. Eğitim kurumları bu bilginin kazanıldığı iş hayatından önceki en önemli kurumlardır. Bu eğitimlerde bilgi ve iletişim teknolojilerini tanıma, kullanma ve eğitim aldıkları alanla ilgili kullanılan bilgi teknolojileri hakkında temel bilgi ve becerileri kazandırma olanağı yaratılmaktadır. Turizm sektörü bilgi, iletișime dayanan emek-yoğun bir sektördür. Bu doğrultuda yapılan bu çalıșmanın amacı; meslek yüksekokulunda turizm ve otelcilik ile aşçılık programlarında eğitim görmekte olan öğrencilerin; bilgi ve iletişim teknolojilerini tanıma ve kullanma becerilerine yönelik yeterliliklerinin belirlenmesi, katılımcıların konu hakkındaki mevcut durumunun ortaya konulmasıdır. Bu kapsamda çalışmanın evreni Afyon Meslek Yüksekokulunda, Otel, Lokanta ve İkram Hizmetlerinde eğitim görmekte olan öğrenciler olarak belirlenmiştir. Calıșmanın teorik ve kavramsal altyapısı literatür doğrultusunda olușturulmuștur. Çalıșmanın uygulama kısmında ise; veri toplamak amacıyla anket tekniği uygulanmıştır. Yapılan analizlerin sonucunda BİT yeterlilik alt ölçeklerine yönelik algılama düzeylerinin hesap çizelgesi programı kullanım yeterliliği hariç orta ve üzeri düzeyde olduğunu işaret etmekte ve katılımcıların bu konuda olumlu yargılara sahip olduğunu göstermektedir. Öğrencilerin demografik ve bireysel özelliklerine göre BİT yeterlilik düzeylerini algılama düzeylerinde istatistiksel açıdan anlamlı bir farklılığın olup olmadığı incelendiğinde; hangi sınıfta oldukları, bilgisayar sahipliği, sertifika/kurs alma, daha önce ders alma durumu, yaş, bilgisayar kullanım süresi ve günlük internet kullanım sürelerine göre anlamlı bir farklılık gösterdiği belirlenmiştir.
\end{abstract}

\section{ABSTRACT}

\section{Keywords:}

Information and communication technologies

Tourism and hotel management

Cookery

Vocational school

Makalenin Türü: Araştırma Makalesi

*Sorumlu Yazar: Hümeyra T. BAŞAT

E posta: humeyratore@gmail.com

\begin{abstract}
Today, information and communication technologies (ICT) increase their importance day by day, as in every field of life; causes great changes in the working conditions and working order of the employees. This juncture make a positive difference between the employees who have the necessary information, skills and hardware to use information and communication technologies effectively and efficiently and accelerate the acceptance of individuals in business life. Educational institutions are the most important institutions that gain this knowledge before the business life. With this educations; recognize and use the information and communication technologies and with the trained area about the information and communication technologies created. Tourism sector is a dense sector based on information, communication and knowledge. The purpose of this study conducted in this direction; students studying in tourism and hotel management and cookery programs in vocational school; determination of their competencies regarding the skills of recognizing and using information and communication technologies, and revealing the current status of the participants on the subject.In this context study's universe is the students that receive education in hotel, restaurant and catering services program. Study's theorical and conceptual infrastructure created according to the literature. In the part of application; survey technique applied to collect data. With this aim, we wat to examine descriptive statistics, mecessities for a quality education and status the students with the subject of technology literacy. As a result of the analysis information and communication tecnologies (ICT) points out the perception levels of the competency subscales are at an intermediate level and above, excluding the use of spreadsheet program and indicates that participants have positive judgments about this issue. When it is examined whether there is a statistically significant difference in the perception levels of the ICT proficiency levels according to the demographic and individual characteristics of the students; It was determined that there was a significant difference according to which class they were in, computer ownership, certificate/course taking, previous course taking status, age, computer usage time and daily internet usage time.
\end{abstract}

Makalenin Künyesi: Başat, H. T., Yllmaz, H. \& Özer, E. (2020). Turizm ve Otelcilik ile Aş̧̧llı Öğrencilerinin Bilgi ve İletişim Teknolojileri Yeterliliklerinin Belirlenmesine Yönelik Bir Araşttrma: Afyon Meslek Yüksekokulu Örneği. AHBVÜ Turizm Fakültesi Dergisi, 23 (1), 97-114 


\section{Ankara Hacı Bayram Veli Üniversitesi Turizm Fakültesi Dergisi \\ Başat, Yılmaz \& Özer, 2020, Cilt: 23, Sayı: 1, 97-114}

\section{GIRIŞ}

Bilgi ve iletişim teknolojilerindeki yaşanan gelişmeler ve değişimler, her geçen gün insan hayatını daha fazla etkilemekte ve kullanımı sürekli artmaktadır. Hayatın her alanında vazgeçilmez bir unsur olarak görülen bilgi ve iletişim teknolojilerindeki yaşanan gelişmeler eğitim alanını da büyük ölçüde etkilemektedir. $\mathrm{Bu}$ nedenle eğitim, bilgi ve teknoloji birbirleriyle ayrılmaz bir bütün olarak değerlendirilmektedir. Eğitim yaklaşımları, eğitim kalitesi, eğitimde kullanılan bilgi ve teknolojik araç gereçler günümüzün eğitim eğilimlerini belirlemektedir. Dolayısıyla bilgi ve teknolojik araçlarında yaşanan gelişmeleri takip edebilmek ve kullanabilmek önemli bir farklılık yaratmaktadır. Bireylerin meslek alanlarıyla ilgili sahip olması gereken nitelikler arasında bilgi ve teknolojiyi etkin bir düzeyde kullanabilmeleri zorunlu hale gelmektedir. Ayrıca eğitimde sadece eğitmenlerin bilgi ve iletişim teknolojilerine sahip olmaları yeterli değildir. Eğitim sürecinin başarılı olabilmesi için öğrencilerin de bilgi ve iletişim teknolojileri konusunda belirli bir düzeyde temel bir alt yapıya sahip olmaları gerekmektedir.

Türkiye'de yükseköğretim düzeyinde, nitelikli insan gücünün yetiştirilmesi için en önemli eğitim kurumlarından birisi de meslek yüksekokullarıdır. Günümüzde iki yıllık eğitim programları doğrultusunda meslek eğitimi veren bu kurumların temel amacı, iş yaşamının gereksinim duyduğu, bilimsel ve teknolojik gelişmelere uyum sağlayabilecek ve kaliteli üretimi gerçekleştirebilecek yüksek nitelikli ara insan gücünün yetiştirilmesini sağlamaktır (Adıgüzel, 2009: 116). Meslek yüksekokulları ara eleman ihtiyacını karşılayan, sektör-okul işbirliği kapsamında ihtiyaçlara göre şekillenen, ülkenin insan kaynakları ihtiyacına göre birçok farklı alanda eğitim veren kurumlardır.

Eğitimde teknoloji entegrasyonu, ülkelerin gelişim planlarında ve eğitsel reform hareketlerinde anahtar rol oynamaktadır. Türkiye'nin takip ettiği uzun dönemli yol haritalarından biri olan TÜBİTAK Vizyon 2023 Projesi'nin ana teması; “'bilim ve teknolojiye hâkim, teknolojiyi bilinçli kullanan ve yeni teknolojiler üretebilen, teknolojik gelişmeleri toplumsal ve ekonomik faydaya dönüştürme yeteneği kazanmış bir refah toplumu yaratmak" olarak belirlenmiştir (Akıncı ve Seferoğlu, 2010: 476). Toplumsal, siyasal, teknolojik ve endüstriyel alanda yaşanan gelişmeler hizmet sektörünüde doğrudan etkilemektedir. $\mathrm{Bu}$ nedenle bilgisayar ve iletişim teknolojilerini kullanmak her meslek alanında zorunlu olduğu gibi emek yoğun bir sektör olarak kabul edilen turizm ve otelcilik alanında da hızla yaygınlaşmaktadır. 
Bu çalışma; Avrupa Bilgisayar Yetkinlik Sertifikası (ECDL) kapsamında, öğrencilerin bilgi ve iletişim teknolojilerindeki yeterliliklerini belirlemek amacıyla gerçekleştirilmiş̧tir. Araştırmanın evrenini 2019-2020 eğitim öğretim yılında, Afyon Kocatepe Üniversitesi, Afyon Meslek Yüksekokulunda, Turizm ve Otel İşletmeciliği ile Aşçılık Programında eğitim görmekte olan öğrenciler oluşturmaktadır. Konu ile ilgili öğrencilere geçerliliği ve güvenilirliği test edilmiş bir anket uygulanmıştır. Anket sonuçları SPSS programıyla değerlendirilmiştir. Anket sonuçlarına göre frekans, ortalama, standart sapmaları içeren tanımlayıcı istatistiksel yöntemler ve t testleri yapılmıştır. Araştırmanın sonuçlarına göre; öğrencilerin donanım, işletim sistemi, kelime işlemci, sunum ve internet yeterlilikler açısından daha iyi düzeyde; ancak hesap çizelgesi yeterliliği açısından daha düşük düzeyde oldukları görülmektedir. Öğrencilerin bilgi ve iletişim teknolojileri kullanım yeterliliklerinde cinsiyetlerine, yaşlarına, bilgisayar sahibi olma durumlarına, bilgisayarı kullanım sürelerine, internete bağlanma sıklıklarına göre farklılıklar bulunduğu belirlenmiştir.

\section{KAVRAMSAL ÇERÇEVE}

Bilgi yönetimi konusunda günümüze kadar yaşanan gelişmeleri yazının keşfi, aritmetik işlemlerin geliştirilmesi ve matbaanın keşfi olarak üç başlık altında toplayabiliriz. Yazının keşfiyle; bilgilerin kayıt edilerek mesaj olarak zaman ve uzayda taşınma olanağı elde edilmiştir. Aritmetik işlemlerle sayısal veriler üzerinde çeşitli işlemler yapılarak, sayısal verilerin doğru ve istenilen sayıda işlemlerden geçirilme firsatı sağlanımıştır. Matbaanın keşfi ise, yazılı metnin benzer kopyalarının çoğaltılması ile çok büyük kitlelere ulaştırılmasını sağlamıştır (Kaya Bensghir, 1996: 29).

Bilginin elde edilmesinde, oluşturulmasında, toplanmasında, yayılmasında, korunmasında teknolojinin yaygın olarak kullanılmaya başlaması, bilgi ve teknoloji kelimelerinin bir arada kullanılmasına, dolayısıyla bilgi teknolojisi kavramının oluşmasına yol açmıştır. Türk Dil Kurumu sözlüğüne göre bilgi teknolojisi, "bilginin toplanmasını, işlenmesi ve saklanmasını, herhangi bir yere iletilmesini, herhangi bir yerden bu bilgiye erişilmesini elektronik vb. yollarla sağlayan teknolojiler bütünüdür”. Bilgiye ulaşmada kullanılan teknolojiler aynı zamanda iletişim amaçlı da kullanılabildiği için bilgi teknolojisi ve iletişim teknolojisi birlikte kullanılmaya başlanmış ve bilgi ve iletişim teknolojileri, kısaca BIT kavramı ortaya çıkmıştır. Bilgi ve iletişim teknolojileri; bilgiyi iletmek, depolamak, yaratmak, paylaşmak için kullanılan radyo, televizyon, video, DVD, telefon (sabit ve mobil), uydu sistemleri, bilgisayar ve ağ donanımı ve yazılımı, ayrıca, bu teknolojiler tarafından sağlanan video konferans ve eposta gibi hizmetlerini kapsamaktadır (UNESCO, 2006). Bilgi ve düşüncenin zaman ve 
mekân sınırı tanımadan hızlı bir şekilde akışını sağlayan görsel, işitsel, yazılı her türlü teknolojik araca "Bilgi ve İletişim Teknolojileri" denmektedir (Tonta, 1999: 365). Bilgi ve iletişim teknolojileri bilginin meydana getirilmesi, yönetilmesi, saklanması, yayılması için kullanılan çeşitli teknolojik araçlar ve kaynaklardır (Blurton, 1999: 46). Başka bir deyişle bilgisayar, mikro elektronik ve telekomünikasyon üçlüsü olarak da adlandırılabilen BIT araçları, bilginin yaratılmasını, toplanmasını, biriktirilmesini, işlenmesini, depolanmasını, ağlar aracılığı ile bir yerden başka bir yere iletilmesini sağlayan araçlardır (Kurtoğlu, 2009: 9). BIT, “iletişim kurmak ve bilgiyi oluşturmak, yaymak, depolamak ve yönetmek için kullanılan çeşitli teknolojik araçlar ve kaynaklar kümesi” şeklinde de tanımlanabilir (Tinio, 2003: 95). Bilgiye ulaşılmasını ve bilginin oluşturulmasını sağlayan tüm görsel, işitsel, basılı ve yazılı araçlar bilgi ve iletişim teknolojileri (BIT) olarak adlandırılmaktadır. Avrupa ülkelerinde bu kavram "Information and Communication Technology (ICT)" olarak kullanılmaktadır (Özgen 2005: 1; Aytaç, 2000). BİT'in sunduğu temel dört özellik şunlardır: Hız, depolama kapasitesi, uğraşsı iletme ve interaktivite (Pritchard, 2007).

21. yüzyılda bireyler ve toplumlar büyük değişim ve dönüşümler yaşamaktadır. Yaşanan bu değişim ve dönüşümün en büyük tetikleyicisi, şüphesiz ki bilgidir. Bilginin miktarında ve bilgiye erişme yollarında meydana gelen bu hızlı değişim, ekonomiden eğitime, sağlıktan tarıma, iletişimden siyasete, üretimden savunmaya kadar toplumun tüm birimlerini etkilemektedir (Gündüz ve Çuhadar, 2006: 355-402). Araştırmalar, BIT destekli öğretimin öğrencilerin eleştirel düşünme, yaratıcı düşünme, problem çözme ve karar alma becerilerinin geliştirilmesinde çok önemli bir rolünün olduğunu göstermiştir (Berson, 1996: 486-499).

Eğitim ve teknoloji birbirini etkileyen unsurlardır. Eğitim amaçlı kullanılan teknolojilerin gelişmesiyle insanların öğrenmesi kolaylaşacak ve doğayı daha iyi anlayacaktır. İnsanların öğrendiklerinin artması ise daha iyi teknolojiler geliştirmesine fırsat sağlayacaktır. Bu nedenle ülkelerin bilim ve teknolojideki gelişmeleri ile eğitimde teknolojiden ne düzeyde yararlandıkları arasında bir ilişki vardır (Bahar, 2006). Eğitim ve teknoloji arasındaki ilişki çağın getirdiği yeniliklerle birlikte sürekli değişmektedir. Bu değişime paralel olarak eğitim ile BIT arasındaki ilişkinin boyutu da zaman ilerledikçe değişmiştir. Başlangıçta bu ilişki BIT'in ayrı bir konu alanı olarak öğretimi biçiminde yapılırken, giderek BIT'in öğrenmeöğretme süreci içerisinde aktif olarak kullanılması, öğretim programı ile BIT’in bütünleştirilmesi, diğer bir deyişle BIT’in öğrenme-öğretme sürecine entegrasyonu durumuna geçilmiştir. BIT'in öğrenme-öğretme sürecine entegrasyonu, öğretim hedeflerini 
gerçekleştirmek ve öğrencilerin öğrenmesini güçlendirmek için BIT araçlarının öğretim programı boyunca kullanılması olarak tanımlanmaktadır (Cartwright ve Hammond, 2003).

Günümüzde hızla gelişen teknoloji ve toplumdaki teknoloji kullanımının artışı göz önüne alınırsa, öğrencileri yaşama hazırlayan kurumlar olarak okulların da bu teknolojiyi kullanmaları ve öğretmeleri gerekmektedir. Bilgisayarlara dayalı bir eğitim ortamında, bilgisayarların yerinde ve etkili olarak kullanıldığı durumlarda öğrenme-öğretme sürecinin daha da zenginleşeceği bir gerçektir (Akkoyunlu, 1995: 106). Eğitim teknolojisindeki yeni gelişmeler öğretim araç-gereçlerine de yansımış, nitelik ve nicelik olarak daha gelişen öğretim araç-gereçlerinin kullanımı eğitim açısından öğretmene, öğrenciye, dersin işlenişine ve eğitimin genel ve özel hedeflerine ulaşma bakımından birçok faydayı da beraberinde getirmiştir (Koşar ve diğ., 2003: 43).

Alanyazında ilgili arastırmalar incelendiğinde, bilgi ve iletişim teknolojileri ile ilgili olarak, bilgi iletişim teknolojilerinin farklı alanlarda kullanımı ve eğitime entegrasyonu ile ilgili çalışmalar yer almaktadır. Ayrıca çalışmalarda, özellikle öğrencilerin ve öğretmenlerin bilgisayar okuryazarlık seviyeleri ve becerileri, bilgi ve iletişim teknolojisi kullanma durumları, bilgi ve iletişim teknolojilerinden yararlanma düzeyleri, bilgi ve iletişim teknolojileri yeterlikleri ve becerileri incelenmiştir. $\mathrm{Bu}$ araştırmalar bilgi ve iletişim teknolojilerinin sürekli gelişmesi nedeniyle zaman zaman tekrarlanmıştır (Tor \& Erden, 2004; Su, 2008; Tella \& Mutula, 2008; Papastergiou, 2010; Luu \& Freeman, 2011; Dinçer \& Şahinkayas1, 2011; Uzunboylu, 1995; Berson, 1996; Demir, 2001; Açıkalın \& Duru, 2005; Volman, Eck, Heemskerk ve Kuiper, 2005; Y1lmaz, 2006; Erol, 2010; Bekar, 2017; Alp, 2019).

\section{YÖNTEM}

Günümüzde bilgi ve iletişim teknolojilerinde yaşanan gelişmeler pek çok sektörde iletişim, koordinasyon, raporlama vb. daha pek çok konuda iş süreçlerinin daha hızlı ve verimli bir şekilde yönetilmesine önemli katkılar sağlamaktadır. Bu kapsamda hizmet kalitesi ve müşteri memnuniyetinin sağlanması noktasında müşteri istek ve beklentilerinin hızlı çözümler gerektirdiği üretim ve tüketimin eş zamanlı olduğu otel işletmelerinde etkin ve hızlı bilgi paylaşımı daha da fazla önem arz etmektedir. Araştırmada tarama modeli uygulanmıştır. Karasar (2014)' a göre araştırmacı yapmış olduğu araştırmasına konu olan olayı, birey ya da nesneyi kendi koşulları içerisinde ve olduğu gibi tanımlamaya çalışıyorsa araştırmasında tarama modelini kullanmalıdır. 
Dolayısıyla, yapılan bu çalışma ile iki yıllık bir eğitim sonrası turizm sektöründe çalışacak olan turizm ve otel işletmeciliği ve aşçılık programı öğrencilerinin bilgi ve iletişim teknolojilerini tanıma ve kullanma becerilerine yönelik yeterliliklerinin belirlenmesi, katılımcıların konu hakkındaki mevcut durumunun ortaya konulması ve eğitim süreci içerinde BİT teknolojileri hakkında aldıkları eğitimlerin etkinliğinin belirlenmesinde ilgili yazına katkı sağlayacağı düşünülmektedir. Bu kapsamda araştırmanın amacı doğrultusunda iki soru cümlesi belirlenmiştir. Bunlardan ilki, “öğrencilerin bilgi ve iletişim teknolojileri yeterlilikleri ne düzeydedir? " ikincisi ise öğrencilerin bilgi ve iletişim teknolojileri yeterlilik düzeyleri ile demografik özellikleri, eğitim gördükleri bölümler, sınıfları, lise mezuniyet alanları, bilgisayar sahiplikleri, BIT ile ilgili ders alma, kursa katılma, günlük bilgisayar kullanma süresi ve internet kullanma süresi gibi özellikleri arasında anlamlı farklılıklar var mıdır?” Bu doğrultuda araştırma sorularını cevaplamak amacıyla test edilecek hipotezler geliştirilmiştir.

Araştırma amacı çerçevesinde test edilecek istatistiksel hipotezler şunlardır:

H1. Katılımcıların BIT algılama düzeyleri ile cinsiyetleri arasında istatistiksel olarak anlamlı bir farklılık vardır.

H2. Katılımcıların BIT algılama düzeyleri ile bölümleri arasında istatistiksel olarak anlamlı bir farklılık vardır.

H3. Katılımcıların I ve II sınıf olmaları ile BIT algılama düzeyleri arasında istatistiksel olarak anlamlı bir farklılık vardır.

H4. Katılımcıların lise mezuniyet düzeyleri ile BIT algılama düzeyleri arasında istatistiksel olarak anlamlı bir farklılık vardır.

H5. Katılımcıların bireysel bilgisayar sahiplikleri ile BIT algılama düzeyleri arasında istatistiksel olarak anlamlı bir farklılık vardır.

H6. Katılımcıların kurs alma ve sertifika sahibi olmaları ile BIT algılama düzeyleri arasında istatistiksel olarak anlamlı bir farklılık vardır.

H7. Katılımcıların daha önceden BIT hakkında ders alıp almama durumları ile BIT algılama düzeyleri arasında istatistiksel olarak anlamlı bir farklılık vardır

H8. Katılımcıların BIT algılama düzeyleri ile yaşları arasında istatistiksel olarak anlamlı bir farklılık vardır. 
H9. Katılımcıların bilgisayar kullanım süresi ile BIT algılama düzeyleri arasında istatistiksel olarak anlamlı bir farklılık vardır.

H10. Katılımcıların günlük internet kullanım süresi ile BIT algılama düzeyleri arasında istatistiksel olarak anlamlı bir farklılık vardır.

Bu araştırmanın evreni Afyon Kocatepe Üniversitesi, Afyon Meslek Yüksek Okulu Turizm ve Otel İşletmeciliği Programı ve Aşçılık I ve II sınıf öğrencilerinden oluşmaktadır. Katılımcıların BIT teknolojisi yeterliliklerinin belirlenmesi amacıyla 01.11.2019-11.11.2019 tarihleri arasında iki bölümden oluşan anket uygulaması gerçekleştirilmiştir. Anketin birinci bölümünde katılımcıların demografik özelliklerine yer verilmiş olup ikinci bölüm ise BIT yeterlilik ölçeklerinden oluşmaktadır. Çalışmada Senem Kara tarafindan 2011 yılında "İlköğretim okullarında görev yapan öğretmenlerin bilgi ve iletişim teknolojileri yeterliliklerinin belirlenmesi: İstanbul Örneği” isimli yüksek lisans tezinde kullanılan anket uygulanmıştır. Yazarla iletişime geçilerek gerekli onay alınmıştır. Ayrıca çalışma okulda uygulanmadan önce üniversitesinin etik kuruluna başvurularak gerekli izinler ve öğrencilere uygulanmadan önce okul yönetiminden de izin alınarak öğrencilere uygulanmıştır. Öğrencilerden ankette kesinlikle isim belirtmemeleri ve gerçek düşüncelerini ifade etmeleri istenmiştir.

Araştırmada kullanılan söz konusu ölçekleri oluşturan her bir madde beşli Likert tipi derecelendirmeye tabi tutulmuş ve katılımcıların maddelere ilişkin katılım düzeyleri; "1=Tamamen Bilmiyorum,, "2= Bilmiyorum”, “3=Orta Düzeyde Biliyorum”, “4=Biliyorum”, “5=Tamamen Biliyorum” şeklinde puanlandırılmıştır.

Öte yandan araştırmanın uygulamalı alan araştırması olması nedeniyle bir takım sınırlamaları içermektedir. Araştırmanın en önemli kısıtlılığı, Afyon Meslek Yüksek Okulu öğrencilerini kapsamasıdır. $\mathrm{Bu}$ nedenle, sonuçlarla ilgili bir genelleme ancak Afyon Meslek Yüksekokulu'na yönelik genellemeleri içerecektir.

Araştırmada 239 öğrenciden elde edilen verilerin analizi, SPSS paket programı kullanılarak bilgisayar ortamında gerçekleştirilmiştir. Öncelikle ankete katılan turizm ve aşçılık programı öğrencilerinin demografik ve diğer özelliklerin belirlenmesinde yüzde ve frekans analizleri yapılmıştır. Sonrasında verilerin güvenirliğini test etmek amacıyla Cronbach's Alpha katsayıları hesaplanmıştır. BIT yeterlilik düzeylerinin tespit edilmesinde ise standart sapma ve aritmetik ortalama analizleri kullanılmıştır. Bununla birlikte araştırmada, öğrencilerin BIT yeterlilik düzeylerine ilişkin algı düzeyleri demografik ve diğer özellikleri ile alt gruplara göre 
karşılaştırılmıştır. Öğrencilerin, BIT yeterlilik algı düzeylerinin karşılaştırmalarda t testi ve varyans analizi kullanılmıştır.

\section{BULGULAR}

Araştırma grubunda yer alan öğrencilerin demografik ve diğer özelliklerine ilişkin yüzde ve frekans dağılımı Tablo 1'de sunulmuştur.

Tablo 1: Katılımcıların demografik özelliklerine göre dağılımı

\begin{tabular}{|c|c|c|c|}
\hline Değişkenler & Gruplar & $\mathbf{F}$ & $\%$ \\
\hline \multirow[b]{2}{*}{ Cinsiyet } & Kadın & 123 & 51,5 \\
\hline & Erkek & 116 & 48,5 \\
\hline \multirow[t]{4}{*}{ Yaş } & $18-20$ & 181 & 75,7 \\
\hline & $21-23$ & 45 & 18,8 \\
\hline & $24-26$ & 3 & 1,3 \\
\hline & 27 ve üzeri & 10 & 4,2 \\
\hline \multirow[t]{2}{*}{ Bölüm } & Turizm ve Otel İşl. & 82 & 34,3 \\
\hline & Aşçıllik & 157 & 65,7 \\
\hline \multirow[b]{2}{*}{ Sinıf } & Birinci sinif & 144 & 60,3 \\
\hline & İkinci sınıf & 95 & 39,7 \\
\hline \multirow[t]{2}{*}{ Mezun olduğu lise } & Turizm meslek lisesi & 50 & 20,9 \\
\hline & Diğer & 189 & 79,1 \\
\hline \multirow[t]{2}{*}{ Bilgisayar sahipliği } & Evet & 130 & 54,4 \\
\hline & Hayır & 109 & 45,6 \\
\hline \multirow[t]{3}{*}{ Bilgisayar kullanım süresi } & $1-5 \mathrm{y} 11$ & 99 & 41,4 \\
\hline & $6-10$ y1l & 88 & 36,8 \\
\hline & 10 y1l ve üzeri & 52 & 21,8 \\
\hline \multirow[t]{4}{*}{ Günlük internet kullanımı } & $1-2$ saat & 46 & 19,2 \\
\hline & 3-4 saat & 105 & 43,9 \\
\hline & $5-6$ saat & 48 & 20,1 \\
\hline & 7 saat ve üzeri & 40 & 16,7 \\
\hline \multirow[t]{2}{*}{ BIT kurs/sertifika alma } & Evet & 23 & 9,6 \\
\hline & Hayır & 216 & 90,4 \\
\hline \multirow[b]{2}{*}{ BIT ders alma } & Evet & 121 & 50,6 \\
\hline & Hayır & 118 & 49,4 \\
\hline
\end{tabular}

Tablo 1'deki sonuçlara göre, katılımcıların \%51,5'i kadın, \%75,7'i 18-20 yaş aralığında, \%34,3'ü turizm, \%65,7'i aşçlık bölümünde, \%60,3'i birinci sınıf, \%20,9'u turizm meslek lisesi mezunu, \%54,4'ü kendi bilgisayarına sahip olduğu, \%41,4’ünin 1-5 y1l aralığında bilgisayar kullanmakta olduğu, \%43,9’u 3-4 saat aralığında günlük internet kullandıkları, \%90,4'ünün kurs/sertifika sahibi olmadığı ve \% 50,6'sının BIT hakkında daha önce ders aldığı tespit edilmiştir. 
Araştırmada kullanılan BIT yeterlilik ölçeğine ilişkin güvenirlik analizleri (Cronbach’s Alpha) sonuçları ile katılımcıların BIT yeterlilik düzeyi ölçeğinde yer alan her bir soruya ve her bir boyuta ilişkin aritmetik ortalama ve standart sapma değerleri Tablo 2'de sunulmuştur.

Tablo 2: Bilgi ve iletişim teknolojisi yeterlilik ölçeğine ilişkin bazı tanıtıcı istatistikler

\begin{tabular}{|c|c|c|c|c|}
\hline Ölçek/Alt Ölçekler & $\begin{array}{l}\text { Madde } \\
\text { Say1s1 }\end{array}$ & Ort & SS & $\begin{array}{l}\text { Cronbach's } \\
\text { Alpha }\end{array}$ \\
\hline Donanım Yeterlilikleri & 6 & 3,36 & $\mathbf{0 , 9 0}$ & $\mathbf{0 , 8 7 8}$ \\
\hline Merkezi işlem birimi (CPU, CPU hızı MHz) & & 2,60 & 1,20 & \\
\hline Bellek (RAM, ROM vb.) & & 3,10 & 1,19 & \\
\hline Giriş birimleri (fare, klavye, tarayıcı, joystick vb.) & & 3,97 & 1,04 & \\
\hline Çıkış birimleri(ekran, monitör, yazıcı, hoparlör vb.) & & 3,98 & 1,01 & \\
\hline Giriş/Çıkış birimleri & & 3,54 & 1,19 & \\
\hline Depolama birimleri(Hız, maliyet, kapasite vb.) & & 2,98 & 1,22 & \\
\hline İșletim sistemi kullanım yeterliliği (YAZILIM) & 6 & 3,36 & $\mathbf{0 , 9 2}$ & $\mathbf{0 , 8 8 8}$ \\
\hline Bilgisayara program kurma ve kaldırma & & 3,02 & 1,30 & \\
\hline Dosyaları klasörlerle düzenleme & & 3,63 & 1,16 & \\
\hline Görüntü ayarlarını (arka plan ayarları, masaüstü simgeler gibi) yapma & & 3,75 & 1,07 & \\
\hline Aynı anda farklı program veya pencere ile çalışma & & 3,61 & 1,12 & \\
\hline Kısa yol tuşları (Kısa yol kullanımı, yeni kısa yol tuşları atama gibi) & & 3,35 & 1,08 & \\
\hline Bilgisayar yazılım yeniliklerini takip etme ve & & 2,84 & 1,14 & \\
\hline Kelime işlemci Programı kullanım yeterliliği (WORD) & 13 & 3,32 & 0,96 & 0,959 \\
\hline Kelime işlemcisiyle ilk adımlar (Aç, kaydet, yeni belge aç, kapat vb.) & & 3,78 & 1,16 & \\
\hline Veri ekleme, seçme, düzenleme & & 3,36 & 1,21 & \\
\hline Kopyalama, taşıma, silme & & 3,95 & 1,9 & \\
\hline Metin biçimlendirme & & 3,44 & 1,17 & \\
\hline Paragraf biçimlendirme & & 3,31 & 1,25 & \\
\hline Belge biçimlendirme & & 3,12 & 1,12 & \\
\hline Stiller ve sayfalama & & 3,10 & 1,17 & \\
\hline Başlıklar ve sayfa altlıkları & & 3,31 & 1,14 & \\
\hline İmla ve gramer Kontrolü & & 3,03 & 1,26 & \\
\hline Tablolar & & 3,13 & 1,19 & \\
\hline Resim, şekiller ve grafikler & & 3,29 & 1,17 & \\
\hline Nesneleri aktarma(Excel tablosunu belgeye aktarma vb) & & 3,05 & 1,10 & \\
\hline Yazdırma seçenekleri ve yazdırma & & 3,38 & 1,20 & \\
\hline Hesap çizelgesi programı kullanım yeterliliği (EXCEL) & 11 & 2,82 & $\mathbf{0 , 8 9}$ & $\mathbf{0 , 9 3 5}$ \\
\hline $\begin{array}{l}\text { Hesap çizelgesi uygulaması ile ilgili ilk adımlar (Aç, kaydet, yeni belge } \\
\text { aç, kapat }\end{array}$ & & 3,47 & 1,26 & \\
\hline Hücreleri seçmek ve veri girişi & & 3,01 & 1,17 & \\
\hline Satırlar ve sütunlar & & 3,18 & 1,20 & \\
\hline Veri değişikliği & & 2,71 & 1,17 & \\
\hline Kopyalama, taşıma, silme & & 3,56 & 1,12 & \\
\hline Aritmetik ve mantık formülleri & & 2,42 & 1,3 & \\
\hline Hücre referans1 verme & & 2,26 & 1,01 & \\
\hline Fonksiyonlarla çalışma & & 2,26 & 1,06 & \\
\hline Sayılar ve günler & & 2,94 & 1,20 & \\
\hline Hücre Biçimlendirme & & 2,48 & 1,15 & \\
\hline Şemalar-grafikleri kullanma & & 2,75 & 1,11 & \\
\hline Sunum programı kullanım yeterliliği (POWER POINT) & 12 & 3,19 & 1,06 & 0,966 \\
\hline Saydamlar (slaytlar) & & 3,38 & 1,20 & \\
\hline Tasarım şablonlarını kullanma & & 3,10 & 1,24 & \\
\hline Saydam (slayt) kopyalama, taşıma, silme & & 3,31 & 1,25 & \\
\hline Metni biçimlendirme & & 3,22 & 1,25 & \\
\hline Resimler ve görüntüler & & 3,39 & 1,18 & \\
\hline Șema / Grafik kullanma & & 3,10 & 1,23 & \\
\hline Çizilmiş nesneler (otomatik şekil) & & 3,03 & 1,26 & \\
\hline Görüntü kopyalama, taşıma, silme & & 3,52 & 1,25 & \\
\hline Önceden belirlenmiş canlandırmalar (animasyon) & & 2,91 & 1,27 & \\
\hline Geçişler & & 3,26 & 1,27 & \\
\hline
\end{tabular}




\begin{tabular}{|c|c|c|c|c|}
\hline Hareketli gif, Film, Animasyon oluşturmak & & 2,90 & 1,37 & \\
\hline Bir sunum gerçekleştirme & & 3,28 & 1,20 & \\
\hline İnternet Kullanım Yeterliliği & 7 & 3,78 & 1,02 & $\mathbf{0 , 9 2 7}$ \\
\hline $\begin{array}{l}\text { Internet tarayıcı programlarını (Explorer, Opera, Safari vb.) } \\
\text { kullanma }\end{array}$ & & 3,62 & 1,38 & \\
\hline İnternetten arama yapabilme ve arama teknikleri & & 4,15 & 1,03 & \\
\hline İnternetten bilgisayara dosya kaydetme & & 3,95 & 1,10 & \\
\hline
\end{tabular}

Tablo 2: Bilgi ve iletişim teknolojisi yeterlilik ölçeğine ilişkin bazı tanıtıcı istatistikler (devam)

\begin{tabular}{|c|c|c|c|c|}
\hline Ölçek/Alt Ölçekler & $\begin{array}{l}\text { Madde } \\
\text { Say1s1 }\end{array}$ & Ort & SS & $\begin{array}{c}\text { Cronbach's } \\
\text { Alpha }\end{array}$ \\
\hline İnternet Kullanım Yeterliliği (devam) & 7 & 3,78 & $\mathbf{1 , 0 2}$ & $\mathbf{0 , 9 2 7}$ \\
\hline E-posta ile iletişim (Dosya ve mesaj gönderme-alma) & & 3,87 & 1,15 & \\
\hline Bilgi alışverişi için tartışma sitelerini ve forumları kullanma & & 3,39 & 1,35 & \\
\hline $\begin{array}{l}\text { Internet üzerinde iletişim araçlarını (Canl1-etkileşimli görsel, işitsel) } \\
\text { kullanma }\end{array}$ & & 3,54 & 1,26 & \\
\hline İnternet üzerinden haberleşme (sesli, görüntülü) & & 3,96 & 1,16 & \\
\hline Genel Yeterlilik & 55 & 3,31 & $\mathbf{0 , 8 0}$ & 0,980 \\
\hline
\end{tabular}

Ölçeğin geneli için Cronbach's Alpha katsayısı $\alpha=0,980$ olarak hesaplanmıştır. Öte yandan alt ölçeklere yönelik hesaplanan Cronbach's Alpha değerlerinin tamamının 0,70 değerinin üzerinde olduğu belirlenmiştir. Bu değerler ölçeklerin iç tutarlık düzeylerinin yeterli olduğunu göstermektedir (Ural ve Kılıç, 2013: 23).

Tablo 2'deki aritmetik ortalamalar incelendiğinde, araştırma grubunda yer alan öğrencilerin donanım yeterlilikleri $(\bar{x}=3,36)$, işletim sistemi kullanım yeterliliği (YAZILIM) $(\bar{x}=3,36)$, kelime işlemci programı kullanım yeterlilikleri (WORD) $(\bar{x}=3,32)$, hesap çizelgesi programı kullanım yeterliliği (EXCEL) $(\overline{\mathrm{X}}=2,82)$, sunum programı kullanım yeterliliği (POWER POINT) $(\bar{x}=3,19)$, İnternet kullanım yeterliliği $(\bar{x}=3,78)$ ve BİT genel yeterlilik $(\bar{x}=3,31)$ ortalamaya sahiptirler.

BIT yeterlilik ölçeğinin alt boyutlarına ilişkin aritmetik ortalama değerleri incelendiğinde ise “internet kullanım yeterliliğì" $(\overline{\mathrm{x}}=3,78)$ boyutuna ilişkin ortalama puanların diğer boyutlardan yüksek olduğu görülmekte iken en düşük ortalamaya sahip boyut hesap çizelgesi programı kullanım yeterliliği (EXCEL) $(\overline{\mathrm{x}}=2,78)$ boyutudur. Tablo 2'deki bulgular katılımcıların BIT yeterlilik alt ölçeklerine yönelik algılama düzeylerinin hesap çizelgesi programı kullanım yeterliliği hariç orta ve üzeri düzeyde olduğunu işaret etmekte ve katılımcıların bu konuda olumlu yargılara sahip olduğunu göstermektedir. $\mathrm{Bu}$ sonuçlar, “Öğrecilerin BIT teknolojilerine yönelik yeterlilikleri ne düzeydedir? ” sorusunu cevaplamaktadir. 
Araştırmanın bu kısmında, öğrencilerin demografik ve bireysel özelliklerine göre BIT yeterlilik düzeylerini algılama düzeylerinde istatistiksel açıdan anlamlı bir farklılığın olup olmadığı," t-testi" ve "Anova" testi sonuçlarına göre ortaya konulmuştur. Bu kapsamda, iki gruplu değişkenlere (cinsiyet, bölüm, sınıf, mezun olduğu lise, bilgisayar sahipliği, sertifika/kurs ve ders alma) göre karşılaştırılmasında " t- Testi”; ikiden fazla grup içeren değişkenlere (yaş, bilgisayar kullanım süresi, günlük internet kullanım süresi) göre karşılaştırılmasında ise "Tek Faktörlü Varyans (Analisis of Variance- F testi) Analizi" uygulanmıştır. Sonuçlar $(\mathrm{p}<0,05)$ anlamlılık düzeyinde yorumlanarak tablolar halinde sunulmuştur.

Tablo 3'de öğrencilerin BIT yeterlilik algılama düzeylerinin karşılaştırılmasına yönelik t-testi sonuçları sunulmuştur. Test sonuçlarına göre, öğrencilerin BIT yeterlilik algılama düzeylerinin hangi sınıfta oldukları, bilgisayar sahipliği, sertifika/kurs alma ve daha önce ders alma durumlarına göre anlamlı bir farklılık gösterdiği belirlenmiştir $(p<0,05)$. Bulgulara göre 2. Sınıf öğrencilerin, bilgisayar ve sertifika sahibi olan öğrencilerin ve daha önce BIT dersi alan öğrencilerin BIT yeterlilik düzeylerinin daha yüksek olduğu tespit edilmiştir.

Tablo 3: Ölçek ve alt ölçek ortalamalarının iki değişkenli gruplara yönelik karşılaştırılmasına ilişkin bulgular (t-testi sonuçları)

\begin{tabular}{|c|c|c|c|c|c|}
\hline Ölçekler/Alt Ölçekler & Gruplar & $\bar{X}$ & SS & $t$ & $\mathbf{p}$ \\
\hline \multirow{2}{*}{$\begin{array}{l}\text { BIT Genel Yeterlilik } \\
\text { Cinsiyet }\end{array}$} & Kadın & 3,26 & 0,80 & \multirow{2}{*}{$-0,898$} & \multirow{2}{*}{0,370} \\
\hline & Erkek & 3,35 & 0,81 & & \\
\hline \multirow{2}{*}{$\begin{array}{l}\text { BIT Genel Yeterlilik } \\
\text { Bölüm }\end{array}$} & Turizm & 3,18 & 0,80 & \multirow{2}{*}{$-0,1775$} & \multirow{2}{*}{0,077} \\
\hline & Aşçılık & 3,37 & 0,80 & & \\
\hline \multirow{2}{*}{$\begin{array}{l}\text { BIT Genel Yeterlilik } \\
\text { Hangi sinıf }\end{array}$} & I.Sinif & 3,08 & 0,77 & \multirow{2}{*}{$-5,721$} & \multirow{2}{*}{$0,000^{*}$} \\
\hline & II.Sinıf & 3,65 & 0,72 & & \\
\hline \multirow{2}{*}{$\begin{array}{l}\text { BIT Genel Yeterlilik } \\
\text { Lise mezuniyeti }\end{array}$} & Tur.Mes Lis & 3,29 & 0,79 & \multirow{2}{*}{$-0,130$} & \multirow{2}{*}{0,897} \\
\hline & Diğer Lise & 3,31 & 0,81 & & \\
\hline \multirow{2}{*}{$\begin{array}{l}\text { BIT Genel Yeterlilik } \\
\text { Bilgisayar sahipliği }\end{array}$} & Evet & 3,52 & 0,76 & \multirow{2}{*}{4,573} & \multirow{2}{*}{0,000 * } \\
\hline & Hayır & 3,05 & 0,79 & & \\
\hline \multirow{2}{*}{$\begin{array}{l}\text { BIT Genel Yeterlilik } \\
\text { BIT Sertifika//kurs alma }\end{array}$} & Evet & 3,94 & 0,60 & \multirow{2}{*}{4,125} & \multirow{2}{*}{$0,000 *$} \\
\hline & Hayır & 3,24 & 0,79 & & \\
\hline \multirow{2}{*}{$\begin{array}{l}\text { BIT Genel Yeterlilik } \\
\text { BIT Ders alma }\end{array}$} & Evet & 3,63 & 0,71 & \multirow{2}{*}{6,873} & \multirow{2}{*}{$0,000^{*}$} \\
\hline & Hayır & 2,97 & 0,75 & & \\
\hline
\end{tabular}

$*_{\mathrm{p}}<0,05$; Gruplar arasında anlamlı farklılık vardır

Tablo 4'de öğrencilerin BIT yeterlilik algılama düzeylerinin yaş, bilgisayar kullanım süreleri ve günlük internet kullanım sürelerine göre karşılaştırılmasına yönelik varyans analizi (ANOVA) sonuçları sunulmuştur. 
Tablo 4: Ölçek ve alt ölçek ortalamalarının ikiden fazla değişkenli gruplara yönelik karşılaştırılmasına ilişkin bulgular (varyans analizi sonuçları)

\begin{tabular}{|c|c|c|c|c|c|}
\hline Ölçekler/Alt ölçekler & Gruplar & $\bar{X}$ & SS & $\mathbf{F}$ & $\mathbf{p}$ \\
\hline \multirow{4}{*}{$\begin{array}{l}\text { BIT Genel Yeterlilik } \\
\text { Yaş }\end{array}$} & $18-20$ & 3,22 & 0,81 & \multirow{4}{*}{3,120} & \multirow{4}{*}{$0,027 *$} \\
\hline & $21-23$ & 3,51 & 0,70 & & \\
\hline & $24-26$ & 3,41 & 0,37 & & \\
\hline & 27 ve üzeri & 3,84 & 0,87 & & \\
\hline \multirow{3}{*}{$\begin{array}{l}\text { BIT Genel Yeterlilik } \\
\text { Kaç yıldır bilgisayar kullanımı }\end{array}$} & $1-5$ y1l & 3,01 & 0,76 & \multirow{3}{*}{14,962} & \multirow{3}{*}{$0,000^{*}$} \\
\hline & $6-10 \mathrm{y} 11$ & 3,39 & 0,79 & & \\
\hline & 10 yll ve üzeri & 3,71 & 0,71 & & \\
\hline \multirow{4}{*}{$\begin{array}{l}\text { BIT Genel Yeterlilik } \\
\text { Günlük internet kullanım süresi }\end{array}$} & $1-2$ saat & 3,16 & 0,72 & \multirow{4}{*}{2,798} & \multirow{4}{*}{$0,041^{*}$} \\
\hline & 3-4 saat & 3,22 & 0,81 & & \\
\hline & 5-6 saat & 3,41 & 0,83 & & \\
\hline & 7 saat ve üzeri & 3,58 & 0,80 & & \\
\hline
\end{tabular}

$* \mathrm{p}<0,05$; Gruplar arasında anlamlı farklılık vardır

Bulgulara göre, öğrencilerin BIT yeterlilik algılama düzeylerinin yaş, bilgisayar kullanım süresi ve günlük internet kullanım sürelerine göre aralarında anlamlı bir farklılık gösterdiği tespit edilmiştir. Bulgulara göre yaş, bilgisayar kullanımı ve günlük internet kullanım süresi daha fazla olan öğrencilerin BIT yeterlilik düzeylerinde de artma görülmektedir.

\section{SONUÇ VE ÖNERILLER}

Bilgi ve iletişim teknolojileri (BIT) insanların zaman ve mekân sınırı tanımadan kullandıkları tüm görsel, işitsel, basılı ve yazılı teknolojik araçlar olarak karşımıza çıkmaktadır. Bilgi ve iletişim teknolojileri (BIT) alanında yaşanan değişim ve dönüşümler, yeniliklerin hızla yayılması; çalışma hayatında teknolojiyi takip edebilen ve etkin kullanarak işletmelere katkı sağlayan çalışanları ön plana çıkarmaktadır.

Eğitim ve teknoloji kavramı birbirini etkileyen ve birbirinden etkilenen unsurlar olarak görülmektedir. Teknolojinin eğitimde kullanılmaya başlanmasıyla eğitim ve öğretim yöntemlerinde köklü değişimler yaşanmaktadır. Günümüzde; öğrencilerin bilgi ve iletişim teknolojilerini, eğitim dönemlerinin her aşamasında, sürekli ve etkileşimli bir şekilde kullandıkları görülmektedir. Bilgi ve iletişim teknolojilerinin eğitimde kullanılması ile öğrenmeyi kolaylaştırma, etkin öğrenme, yaratıcı düşünme, başarı ve motivasyon artışı sağlanmaktadır.

Araştırmanın amacı, Afyon Meslek Yüksek Okulu Turizm ve Otel İşletmeciliği programında eğitim alan I ve II sınıf öğrencilerinin Avrupa Bilgisayar Yetkinlik Sertifikası (ECDL) kapsamında, bilgi ve iletişim teknolojilerindeki yeterliliklerini belirlemek amaciyla gerçekleştirilmiştir. Araştırmanın amacı doğrultusunda iki soru cümlesi belirlenmiştir. 
Bunlardan ilki, "katılımcıların BIT teknolojilerine yönelik yeterlilikleri ne düzeydedir?" ikincisi ise " katılımcıların BIT teknolojilerini kullanma düzeyleri ile demografik ve diğer özellikleri arasında anlamlı farklılıklar var mıdır?”. Araştırmada tarama modeli uygulanmıştır. $\mathrm{Bu}$ çerçevede Senem Kara tarafından geliştirilen anket, 2019-2020 eğitim öğretim yılında, Afyon Kocatepe Üniversitesi, Afyon Meslek Yüksekokulunda, Turizm ve Otel İşletmeciliği Programında eğitim görmekte olan öğrencilere uygulanmıştır. 239 anket SPSS programıyla değerlendirilmiştir. Anket sonuçlarına göre frekans, ortalama, standart sapmaları içeren tanımlayıcı istatistiksel yöntemler ve t testleri yapılmıştır. Araştırmada kullanılan BIT yeterlilik ölçeğine ilişkin güvenirlik analizleri (Cronbach's Alpha) sonucunda ölçeğin geneli için Cronbach's Alpha katsayısı $\alpha=0,980$ olarak hesaplanmıştır.

Öğrencilerin demografik ve bireysel özelliklerine göre BIT yeterlilik düzeylerini algılama düzeylerinde istatistiksel açıdan anlamlı bir farklılığın olup olmadığı," t-testi” ve "Anova" testi sonuçlarına göre ortaya konulmuştur. Test sonuçlarına göre, öğrencilerin BIT yeterlilik algılama düzeylerinin hangi sınıfta oldukları, bilgisayar sahipliği, sertifika/kurs alma ve daha önce ders alma durumlarına göre anlamlı bir farklılık gösterdiği belirlenmiştir. Bulgulara göre 2. Sınıf öğrencilerin, bilgisayar ve sertifika sahibi olan öğrencilerin ve daha önce BIT dersi alan öğrencilerin BIT yeterlilik düzeylerinin daha yüksek olduğu tespit edilmiştir. Varyans analizi (ANOVA) sonuçlarına göre öğrencilerin BIT yeterlilik algılama düzeylerinin yaş, bilgisayar kullanım süresi ve günlük internet kullanım sürelerine göre aralarında anlamlı bir farklılık gösterdiği tespit edilmiştir. Bulgulara göre yaş, bilgisayar kullanımı ve günlük internet kullanım süresi daha fazla olan öğrencilerin BIT yeterlilik düzeylerinde de artma görülmektedir.

Eryılmaz (2018) tarafından Gazi Üniversitesi Turizm Fakültesi’nde gerçekleştirilen benzer bir çalışmada; kelime işlemci programı, internet kullanımı ve işletim sistemi kullanımı yeterliklerinin, donanım bilgi düzeyi, elektronik tablo bilgi düzeyi ve sunu programı bilgi düzeyi yeterliklerine göre daha yüksek olduğu sonucuna ulaşılmıştır. Şad ve Nalçacı'nın (2015); öğretmen adaylarının eğitimde BIT kullanmaya ilişkin yeterliliklerini belirlemek üzere yaptıkları çalışmada; öğretmen adaylarının ders materyallerini hazırlarken interneti kullanabilme; bilgisayarda ders notu, sunum, çalışma kâğıdı vb. hazırlayabilme ve ders materyali hazırlarken Word, Excel, Powerpoint vb. yazılımlardan faydalanma konusunda kendilerini nispeten daha fazla yeterli hissettikleri anlaşılmıştır. Şimşek (2018) tarafından hazırlanan yüksek lisans tezinde; spor eğitimi alan üniversite öğrencileri üzerinde yaptığ çalışmada, yazılım kullanımı ve sanal ortamda iletişim boyutlarının fakültede öğrenim gören 
öğrencilerin yüksekokulda eğitim gören öğrencilere göre tutumlarının daha yüksek olduğu tespit edilmiştir. Araştırmaya katılan öğrencilerin bilgi ve iletişim teknolojilerine yönelik tutumlarına bakıldığında, bilgisayar donanım boyutunda erkek öğrencilerinin tutumlarının kadın öğrencilere göre daha yüksek olduğu sonucuna varılmıştır. Gülcan (2015) tarafindan hazırlanan yüksek lisans tezinde; Sahil Güvenlik Komutanlığı Personeline uygulanan çalışmada; kelime işlemci programı, internet kullanımı ve işletim sistemi kullanımı yeterliklerinin, donanım bilgi düzeyi, elektronik tablo bilgi düzeyi ve sunu programı bilgi düzeyi yeterliklerine göre daha yüksek olduğu sonucuna ulaşılmıştır. Özellikle personelin eğitim durumları yükseldikçe ve bilgi teknolojileri ile ilgili herhangi bir eğitim/kurs programına katıldıkça bilgi ve iletişim teknolojileri yeterliklerinin arttığı belirlenmiştir. Kara (2011) hazırlanan yüksek lisans tezinde; ilköğretimde görev yapan öğretmenlerin donanım, işletim sistemi, kelime işlemci, sunum ve internet yeterlilikleri açısından iyi düzeyde; ancak hesap çizelgesi yeterliliği açısından orta düzeyde oldukları görülmektedir. Öğretmenlerin bilgi ve iletişim teknolojileri kullanım yeterliliklerinde cinsiyetlerine, yaşlarına, hizmet sürelerine, öğrenim düzeylerine, bilgisayar sahibi olma durumlarına, bilgisayarı kullanım sürelerine, internete bağlanma sıklıklarına ve ilköğretimin hangi kademesinde görev yaptıklarına göre farklılıklar bulunduğu belirlenmiştir. Alp (2019) tarafından hazırlanan yüksek lisans tezinde; üniversite öğrencileri üzerinde yapılan çalışmada, BIT'ten kelime işlemci programı, elektronik tablo programı, sunum programı ve internet kullanımı bilgi düzeylerinin öğrencilerin cinsiyetlerine göre anlamlı bir şekilde farklılaşmadığ öğrencilerin donanım ve işletim sistemi kullanımı bilgi düzeylerinin kadın öğrencilerden daha yüksek olduğu tespit edilmiştir.

Yapılan bu çalışma ile iki yıllık bir eğitim sonrası turizm sektöründe çalışacak olan turizm ve otel işletmeciliği ve aşçılık programı öğrencilerinin bilgi ve iletişim teknolojilerini tanıma ve kullanma becerilerine yönelik yeterliliklerinin belirlenmesi, katılımcıların konu hakkındaki mevcut durumunun ortaya konulması ve eğitim süreci içerinde BIT teknolojileri hakkında aldıkları eğitimlerin etkinliğinin belirlenmesi noktasında ilgili yazına katkı sağlayacağı düşünülmektedir.

Yapılan çalışmanın sonuçlarına göre;

- Öğrencilerin BIT yeterlilik düzeyinin yükseltilebilmesi için eğitim kurumlarında bilgi ve iletişim teknolojilerine yönelik uygulamalı ve teorik ders içeriklerine daha fazla ağırlık verilmesi, 
- Sektörde kullanılan otomasyon programlarının takip edilmesi ve ders içeriklerine yansitilmasi,

- Turizm eğitimi kapsamında yer alan programların çoğunun uygulamalı olması nedeniyle öğrencilerin iş hayatında kullanmak zorunda kalabileceği bilgisayar yazılımlarına ve otomasyon sistemlerine ders içeriklerinde daha fazla yer verilmesi,

- Okullarda yer alan uygulama derslerinin gerçekleştirildiği atölye, laboratuvar, mutfak, stüdyo gibi alanların yanı sıra bilgisayar salonları, simülasyon sınıfları gibi teknolojik altyapı gerektiren ortamların yer alması,

- Uygulama derslerinin yanı sıra teorik derslerde de BIT'e yönelik bilgi düzeyini arttıracak destekleyici çalışmalar ve sektörel uygulamalar yapılması,

- Konu ile ilgili kurslar ve eğitimler düzenlenmesi,

- Eğitimde BIT devamlılı̆̆ı ve kalitesini artıracak yönde çalışmalar yapılması,

- Ders veren eğiticimlerin BIT ile ilgili gelişmeleri takip etmesi ve rehberlik yapabilmesi,

- Ayrıca yöneticilerin öğrencileri ve öğreticileri desteklemesi,

- Konu ile ilgili sürekli yaşanan gelişmelerin ve uygulamaların takip edilmesi ve eğitim kurumlarında uygulanmas1,

önerilmektedir.

\section{KAYNAKÇA}

Açıkalın, M. \& Duru, E. (2005). The Use of Computer Technologies in the Social Studies Classroom. Turkish Online Journal of Educational Technology, Vol. 4, Issue 2; 18-26.

Adıgüzel, O. C. (2009). Meslek Yüksekokulu Öğrencilerinin İşyeri Eğitimi Öğrenme Ürünlerinin Değerlendirilmesi. On Dokuz Mayıs Üniversitesi Eğitim Fakültesi Dergisi, 27: 115-128.

Akıncı, A. \& Seferoğlu, S. S. (2010). Teknoloji Politikaları, Kurumsal Vizyon Çalışmaları ve Eğitime Yansimalar. 4th International Computer and Instructional Technologies Symposium, Konya, $52-56$.

Akkoyunlu, B. (1995). Bilgi Teknolojilerinin Okullarda Kullanımı ve Öğretmenlerin Rolü. Hacettepe Üniversitesi Eğitim Fakültesi Dergisi, 105-109.

Alp, M. (2019). Üniversite Öğrencilerinin Bilgi ve İletişim Teknolojileri Yeterlilikleri ve Kullanım Düzeylerinin Belirlenmesi (Yayınlanmamış yüksek lisans tezi), Ufuk Üniversitesi Sosyal Bilimler Enstitüsü, Ankara. 


\section{Ankara Hacı Bayram Veli Üniversitesi Turizm Fakültesi Dergisi \\ Başat, Yılmaz \& Özer, 2020, Cilt: 23, Sayı: 1, 97-114}

Aytaç, T. (2000). Bilgi Toplumundan Post Modern Topluma Geçiş Sürecinde Eğitim Paradigmalarının

Değişimi.2020 ve Ötesi. Kara Kuvvetleri Eğitim ve Doktrin Komutanlığı, Ankara.

Bahar, M. (2006). Fen ve teknoloji öğretimi. Ankara: Pegem Akademi Yayıncılık.

Bekar, N. (2017). Beden Eğitimi Öğretmen Adaylarının Bilişim Teknolojilerine Yönelik Tutumlarının İncelenmesi (Yayınlanmamış yüksek lisans tezi), Bartın Üniversitesi, Eğitim Bilimleri Enstitüsü, Bartın.

Berson, M. J. (1996). Effectiveness of Computer Technology in Social Studies: A Review of the Literature. Journal of Research on Computing in Education, Vol. 28, Issue 4; 486-499.

Blurton, C. (1999). UNESCO's World Communication and Information Report 1999-2000.

Cartwright, V. \& Hammond, M. (2003), The integration and embedding of ICT into the school curriculum: more questions than answers, Paper presented at the ITTE 2003 Annual Conference of the Association of Information Technology for Teacher Education, Trinity and All Saints College, Leeds.

Demir, S. (2001). Öğretim Elemanı ve Öğrencilerin İnternetin Öğretim Amaçl1 Kullanımına İlişkin Görüş ve Tutumlarının İncelenmesi: Gaziantep Üniversitesi Fen Edebiyat Fakültesi Örneği (Yayınlanmamış yüksek lisans tezi), Gaziantep Üniversitesi Sosyal Bilimler Enstitüsü, Gaziantep.

Dinçer, S. \& Şahinkayası, Y. (2011). A cross-cultural study of ICT competency, attitude and satisfaction of Turkish, Polish and Czech university students. The Turkish Online Journal of Educational Technology - TOJET, 10(4), 31-38.

Erol, O. (2010). Meslek Yüksekokulu Öğrencilerinin Bilgi ve İletişim Teknolojilerini Kullanma Sıklıkları ile Yaratııılık Algıları Arasındaki İlişkinin İncelenmesi (Yayınlanmamış yüksek lisans tezi), Süleyman Demirel Üniversitesi Fen Bilimleri Enstitüsü, Isparta.

Eryılmaz, S. (2018). Öğrencilerin Bilgi ve İletişim Teknolojileri Yeterliliklerinin Belirlenmesi: Gazi Üniversitesi, Turizm Fakültesi Dergisi. Elektronik Sosyal Bilimler Dergisi. Kış-2018, Cilt: 17, Say1: $65,37-49$.

Gülcan, M. (2015). Türk Silahlı Kuvvetleri Personelinin Bilgi ve İletişim Teknolojileri Yeterliliklerinin Belirlenmesine İlişkin Araştırma (Sahil Güvenlik Komutanlığı Örneği) (Yayınlanmamış yüksek lisans tezi), Gazi Üniversitesi Eğitim Bilimleri Enstitüsü, Ankara.

Gündüz S, \& Çuhadar, C. (2006). Bilisim teknolojilerinin sosyal yapı üzerindeki etkileri ve eğitimdeki yeri. Günes, A. (Ed.) Bilgisayar I temel bilgisayar becerileri. Ankara: PegemA Yayıncılık. $355-402$.

Kara, S. (2011). İlköğretim Okullarında Görev Yapan Öğretmenlerin Bilgi ve İletişim Teknolojileri Yeterliliklerinin Belirlenmesi: İstanbul Örneği (Yayınlanmamış yüksek lisans tezi), Bahçeşehir Üniversitesi Fen Bilimleri Enstitüsü, İstanbul.

Karasar, N. (2014). Bilimsel araştırma yöntemi (26. Basım). Nobel Yayın ve Dağıtım, Ankara. 


\section{Ankara Hacı Bayram Veli Üniversitesi Turizm Fakültesi Dergisi \\ Başat, Yılmaz \& Özer, 2020, Cilt: 23, Sayı: 1, 97-114}

Kaya Bensghir, T. (1996). Bilgi Teknolojileri ve Örgütsel Değişim. Ankara: Türkiye ve Ortadoğu Amme İdaresi Enstitüsü, TODAİE Yayın No: 274.

Koşar, E., Yüksel, S. Özkılıç, R. Avcı, U. Alyas, Y., Çiğdem, H. (2003). Öğretim Teknolojileri ve Materyal Geliştirme, PegemA Yayınları, Ankara.

Kurtoğlu, M. (2009). İlköğretim Okullarında Görev Yapan Öğretmenlerin Bilgi Ve İletisim Teknolojilerinin Öğretme-Öğrenme Sürecine Entegrasyonu Hakkındaki Görüşlerinin Yeniliğin Yayılımı Kuramı Temelinde İncelenmesi (Yayınlanmamış yüksek lisans tezi), Çukurova Üniversitesi, Sosyal Bilimler Enstitüsü, Adana.

Luu, K. \& Freeman, J. G. (2011). An analysis of the relationship between information and communication technology (ICT) and scientific literacy in Canada and Australia. Computers \& Education, 56, 1072-1082.

Özgen, Ç. (2005). Avrupa birliği'ne üye 15 ülkede ve Türkiye'de ilköğretim birinci kademe bilgisayar ders programlarının karşılaştırılması ve Türkiye'deki durumun değerlendirilmesi (Yayınlanmamış yüksek lisans tezi), Ankara Üniversitesi, Eğitim Bilimleri Enstitüsü, Ankara.

Papastergiou, M. (2010). Enhancing Physical Education and Sport Science students' self-efficacy and attitudes regarding information and communication technologies through a computer literacy course. Computers \& Education, 54, 298-308.

Pritchard, A. (2007). Effective Teaching with the Internet Technologies: Pedagogy and Practice. London: Paul Chapman Publishing.

$\mathrm{Su}$, K. D. (2008). An integrated science course designed with information communication technologies to enhance university students' learning performance. Computers \& Education, $51,1365-1374$.

Şad, S. N. \& Nalçacı Ö. İ. (2015). Öğretmen Adaylarının Eğitimde Bilgi ve İletişim Teknolojilerini Kullanmaya İlişkin Yeterlilik Algıları. Mersin Üniversitesi Eğitim Fakültesi Dergisi, Cilt 11, Sayı 1, 177-197.

Şimşek, A. (2018). Spor Eğitimi Alan Üniversite Öğrencilerinin Bilgi ve İletişim Teknolojilerine Yönelik Tutumlarının Belirlenmesi (Yayınlanmamış yüksek lisans tezi), Fırat Üniversitesi Sağlık Bilimleri Enstitüsü, Elazığ.

Tella, A. \& Mutula, S. M. (2008). Gender differences in computer literacy among undergraduate students at the university of Botswana: implications for library use. Malaysian Journal of Library \& Information Science, 13(1), 59-76.

Tor, H. \& Erden, O. (2004). İlköğretim öğrencilerinin bilgi teknolojilerinden yararlanma düzeyleri üzerine bir araştırma. The Turkish Online Journal of Educational Technology - TOJET, 3(1), $120-130$.

Türk Dil Kurumu, https://sozluk.gov.tr/, Erişim Tarihi: 06.10.2019.

Tinio, V. L. (2003). ICT in Education. New York: Bureau for Development Policy. 
Tonta, Y. (1999). Bilgi toplumu ve bilgi teknolojisi. Türk Kütüphaneciliği, 13(4), 363-375.

UNESCO, (2006). Using ICT to Develop Literacy. UNESCO Bangkok, 18-21.

Ural, A. ve Kılıç, İ. (2013). Bilimsel Araştırma Süreci ve SPSS İle Veri Analizi, (4. Baskı). Ankara: Detay Yayınc1lik.

Uzunboylu, H. (1995). Bilgisayar Öğrenme Düzeyi İle Bilgisayara Yönelik Tutumlar Arasındaki İlişki (Yayınlanmamış yüksek lisans tezi), Ankara Üniversitesi Sosyal Bilimler Enstitüsü, Ankara.

Yılmaz, G. (2006). Eğitim Fakültesinde Eğitim Görmekte Olan Öğretmen Adaylarının Bilgisayar ve İnternet Kullanımına Yönelik Tutumlarının Belirlenmesi (Yayınlanmamış yüksek lisans tezi), Celal Bayar Üniversitesi Sosyal Bilimler Enstitüsü, Manisa.

Volman, M., Eck, E., Heemskerk, I. and Kuiper, E. (2005). New Technologies, New Differences. Gender and Ethnic Differences in Pupils Use of ICT in Primary and Secondary Education. Computers and Education, Vol. 45; 35-55. 